\title{
Pode a Seleção de Pessoal ser Computadorizada?
}

THOMAS P. FERENCE

In "Personnel - The Management of People at Work, Nov/December, 1968

Tradução de Maria José da Luz Vaz

Os discursos de pós-jantar e de outras ocasiōes de confraternização grupal estão freqüentemente repletos de anedotas demonstrativas do "toque humano" como parte da vitória de inúmeros empreendimentos. Gerentes de vendas orgulham-se de sua habilidade em identificar o vendedor nato. Entrevistadores para admissão em Faculdades relatam casos de quando êles jogaram com a sorte e admitiram estudantes, apesar de tais e tais antecedentes, baseados num discernimento especial, obtido numa entrevista.

Embora os processos de recrutamento e seleção apliquem teòricamente critérios formais de modo objetivo, o fato é que a decisão de empregar um determinado pretendento ou aceitar um certo emprêgo é afetada de maneira significativa por muitos fatôres subjetivos. Damos respeitabilidade a êsses fatôres tôda vez que louvamos a intuição e a sensibilidade interpessoal ou, nesse campo, sempre que as decisões não resultem tăo vitoriosas e nós culpamos o mau julgamento.

A subordinação à intuição, à dinâmica da personalidade $e$ aos palpites educados tem conduzido a perguntas sôbre a possibilidade de desenvolvimento de procedimento objetivos de seleção. Os críticos sustentam que os julgamentos baseados

Thomas P. Ference, professor assistente de comércio na Graduate School of Business, da Universidade de Colúmbia, recebeu seu Ph. D. (doutor em Filosofia) da Universidade Carnegie-Mellon, tendo como tema principal psicologia organizacional. Serve, comumente, como consultor de pesquisas da Arquidiocese de Nova Iorque, onde está interessado antes de mais nada pelas políticas de pessoal de longo alcance e estrutura organizacional, e está também terminando um estudo das decisōes de escolha de emprêgo dos graduados em M.B.A. (Master of Business Administration, ou seja: Mestre em Administração de Emprêsas). 
em critérios subjetivos estão no nível da superstição ou dos estereótipos. 2 Podemos realmente julgar a habilidade de um homem como vendedor pelo seu apêrto de mão, ou seu potencial como dirigente, pelo talhe de seu queixo? Pode um jovem diplomado decidir-se a respeito de uma colocação, baseado em quão bem êle se deu com o entrevistador da companhia?

\section{EVITANDO FRAQUEZAS}

\section{HUMANAS}

Muitos estudantes fracassam na obtenção do diploma na Faculdade; novos empregados freqüentemente descobrem que suas responsabilidades e oportunidades não estão de acôrdo com suas expectativas, e a reciproca pode ser verdadeira do ponto-de-vista da companhia. Portanto, parece razoável perguntar se a melhoria nessas áreas pode ser conseguida através de maior objetividade via computadorização ${ }^{3}$ das decisões de seleção.

0 dirigente ou administrador que está pensando em automatizar seu sistema de seleção precisa antes determinar de que maneira o êxito da sua atuação geral está relacionado com o o toque humano. Tem a intuição pessoal contribuído para desempenho satisfatório, ou a organização tem sido prejudicada por processos baseados em muita confiança nos intangíveis?

Em todo processo de seleção, em primeiro lugar, devem ser conhecidos os atributos do candidato qualificado - que habilidades deve ter um torneiro-mecânico, e que credenciais um calouro universitário precisa apresentar? Segundo: precisam ser desenvolvidos métodos para medir o grau de domínio dos atributos necessários. Terceiro: tem de haver um procedimento para combinar as várias habilidades e para classificar combinaçôes diferentes. Se êstes três conjuntos de informação podem ser determinados com precisão, o passo para a seleção por meio de computador é relativamente simples, e mesmo se houver alguma ambigüidade, novas técnicas de programação heurística podem ser usadas para resolvê-la.

\section{A CAPACIDADE DO COMPUTADOR}

Mesmo se a computadorização das decisões de seleção fôssem desejáveis, ainda assim, muitos problemas técnicos teriam de ser resolvidos antes que ela fôsse possível. Os três passos descritos acima fazem pesadas exigências ao sistema de aquisição de informação da organizaçăo. Por uma simples razão: nem sempre é conhecido o que caracteriza um bom gerente, um bom vendedor, ou um bom estudante. $E$, ainda que isso fôsse conhecido, existe incerteza sôbre quais são as melhores técnicas para medir habilidades e atitudes. Ademais, ninguém pode pormenorizar de que modo o domínio de um tipo de perícia pode compensar a ausência de outra.

Diante disso, essas limitaçōes parecem tornar impossível programar um

2 Os estereótipos aqui se referem aos "clichês mentais", como quando definimos um alemáo como sendo "homem loucu quando diro que bebe muita cerveja" ou quandos clzemos - contra tôdas as verificaçe o braentíficas e pesquisas feitas - que o amisileiro "é homem preguiçoso". Em Homem nistraçáo, temos o estereótipo do fue sabe de RP: um jovem de terno cinza que náo beber elegantemente seu "scoth"

fala em voz alta... (N.T.) 3 Náo confundir "computadorizar" com
computar". 
computador para tomar decisões de seleção. Mas o defensor da computadorização não vê essas dificuldades como argumentos contra a automatização do processo. Antes, para êle isso vem demonstrar a atual falta de estrutura, na área da seleção, e indica que a tomada de decisões pelos computadores seria uma melhora nas práticas usuais eliminando o êrro humano no interpretar os dados à disposição.

O argumento pró-computador é o de que se um empregador quer seguir um procedimento de seleção consistente e ter certeza de que cada candidato recebe atenção equivalente, êle sair-se-á muito melhor com um sistema automatizado, porque os mesmos dados serão colhidos de todos os candidatos e a possibilidade de exClusão acidental ou falha de interpretação seriam reduzidas. Levado ao extremo, esta posição sugere que a tomada de decisões automatizadas deve ser preferida em qualquer situação, não importa quão incompletos os dados à disposição, uma vez que erros ocasionais de percepção, memória, e influências pessoais seriam excluídos.

\section{UM ESTUDO CONFIRMATIVO}

Este quadro promissor foi examinado por estudantes da Graduate School of Business da Universidade de Colúmbia. Entre as aplicações esPecíficas que estudaram, incluem-se de administrações de Faculdades, rerecrutamento coletivo e programas de seleção, além de escolha entre muitas ofertas de emprêgo pelos diplomados como Mestres em Administra- ção de Negócios (M.B.A.). As análises dos estudantes focalizaram primeiramente as exigências de informações e a combinaçăo de diversos fatôres e concluíram que, dada a probabilidade de erros humanos de processamento, a computadorização apresenta uma alternativa desejável ao tomador de decisão que quer realizar uma avaliação consistente de um grupo de candidatos. Dentro dos limites das medidas de desempenho que podem ser obtidas, a validação pode ser levada avante, automática e continuamente, e os resultados dos estudos de validade poderiam então ser empregados pelo programa do computador para adaptar as regras de decisão.

Êstes investigadores também concordam em que os problemas tecnológicos dos sistemas de seleção computadorizadas parecem não apresentar nenhum obstáculo intransponivel. Há, não obstante, complexidades na programação de tais sistemas, e poderia ser necessário desenvolver tanto heurísticas como indices sumários para reduzir o grupo de pretendentes considerados.

\section{O PONTO DE PARTIDA DO PED 4}

Esta análise enfatiza a conveniência de sistemas de seleção computadorizada, mas não arrosta os fatôres subjacentes à decisăo de automatizar nem os julgamentos que o gerente deve proferir com vistas às medidas a serem tomadas e os pesos a serem empregados. Concedido que, dados um conjunto de critérios e outro de medidas, o sistema de seleção automa-

4 PED - Processamento eletrônico de dados. $\mathrm{Fm}$ inglês: EDP (Blectronic data processing). 
tizada fornecerá uma avalização consistente e objetiva dos pretendentes, o certo é que alguém terá de determinar a soma inicial de critérios e dados, bem como as regras de comparação.

Estes poderiam ser derivados da observação de processos correntes; so o objetivo é obter consistência nos procedimentos, precisamos apenas observar o selecionador encarregado avaliando uma série de pretendentes e então, por meio de protocolos e entrevistas, deduzir as regras que êle tenta aplicar.

O primeiro programa empregaria as mesmas regras de decisão, com a garantia de aplicação consistente em todos os casos. Depois que o programa inicial fôr desenvolvido, a validação e a precisão aumentada das medidas e dos critérios podem seguir-se, isto é, regras apropriadas de decisão podem desabrochar, a tempo, do funcionamento do sistema.

Tudo isto soa muito persuasivo. Há problemas técnicos a serem resolvidos e, talvez, estudos a serem iniciados, e há algumas decisões e julgamentos a serem feitos, mas no conjunto a mecânica do sistema de seleção computadorizada parece utilizável ou aberta a franco desenvolvimento. Dada essa promessa de objetividade e uniformidade na avaliação dos pretendentes, deveriamos esperar a emersão de uma forte tendência em direção à adoção dos processos computadorizados pelos chefes de pessoal, departamentos de admissão e assemelhados. Tal tendência pode existir, mas há muitos fatôres que poderiam retardá-la.

\section{QUANTO VALE A CONSISTENCIA?}

Em primeiro lugar, a consistência e a uniformidade, tornadas possiveis pela seleção computadorizada, podem não ser de muita vantagem em algumas organizações. Podem êles tirar proveito dêsses atributos, ou cada decisão de seleção é diferente das demais? No último caso, tornar-se-ia necessário definir um critério ajustado para cada posição a ser preenchida, possivelmente um processo tedioso e caro. A consistência năo é particularmente relevante, caso um gerente de mercado seja contratado apenas uma vez cada cinco anos. Tantas alterações podem dar-se na companhia, que os critérios aplicados na decisão anterior podem não mais ser apropriados. Por outro lado, a consistência pode ser muito desejável no preenchimento de quinhentos lugares na classe de calouros de uma Faculdade.

Evidentemente, a decisão de automatizar depende do grau de repetição no sistema de seleção, e a relativa eficiência do sistema computadorizado aumentaria em proporção direta ao número de decisões semelhantes a serem feitas.

Deve ser realçado que o uso de processos de seleção consistente năo implica necessàriamente em que 0 grupo de pretendentes vitoriosos seja idêntico ou indiferenciado sob todos os aspectos. A sugestão de computadorização freqüentemente traz à luz o espectro da conformidade, estagnação e mediocridade. $\mathrm{Na}$ realidade, considerável flexibilidade pode ser erigida em regras de decisão. Características diferentes poderiam ser con- 
sideradas como comparáveis, ou distribuições apetecidas de vários atributos poderiam ser incluídas nessas regras. Um processo de seleção automatizada define algumas, mas não tôdas características de um pretendente aceitável, e não há motivo para supor que individualidade, imaginação e criatividade sejam eliminadas por tal sistema.

\section{ALÉM DA MENSURAÇÃO MECÂNICA}

Há, entretanto, implicações subjetivas na adoção da automatização. Em algumas situações, a avaliação de uma pessoa por outra é aspecto essencial do processo de seleção. Pode muito bem existirem caracteristicas individuais que sejam determinantes-chave do desempenho, mas não possam ser medidas objetivamente, e o julgamento do especialista de seleção sensitivo e experiente pode ser o único meio de detectar êsses intangiveis vitais. A tó no toque humano é exemplificada pela entrevista pessoal ou pelo almôSo no qual o interêsse por um candidato é avaliado; se a compatibilidade social de alguém com os companhelros de trabalho fôr de molde a afetar o desempenho, esta confrontação pessoal pode ser crucial para a decisão de seleção.

Se o encarregado da seleçăo é excepcionalmente sensitivo ou se existem qualidades relativamente intangiVeis que têm mútua relação com a eficiência em algumas ocupações, provàvelmente decidiria contra a computadorização do sistema de seleção. Aqui, a situação é mais ou menos parecida com a escolha de cônjuge. Programas de computador que combinam casais na base de compatibilidade, por meio de diversos critérios, têm merecido muita publicidade nos últimos anos. Inscrevendo-se numa dessas operaçōes, a pessoa pode ser apresentada a bom número de parceiros em potencial, mas os programas predizem apenas que o par será compativel. Se o casamento acontece ou não, e se tiver êxito, depende da sensibilidade do casal para avaliar intangíveis. Ninguém deixaria a decisão de com quem casar-se para o computador, e se postos a serem preenchidos envolvem similarmente tais intangiveis, o gerente de seleção deveria insistir em conservar o julgamento humano como o elemento crítico na sua decisão.

\section{OS PONTOS DA INTUIÇÃO}

O tomador de decisões deve julgar o grau em que a sensibilidade interpessoal afeta realmente o êxito das decisões de seleção. Todos podem apontar exemplos de terem se arriscado com um pretendente que não condizia muito com os padrões usuais, mas que, como veio a acontecer, desempenharam-se extremamente bem. Êstes casos são citados para justificar pretensões de clarividência especial quanto às potencialidades do nosso próximo, mas o tomador de decisões deve considerar se sua recordação de tais casos é correta.

Ao invés de simplesmente indicar um número de palpites acertados, precisa conferir a proporção de tais julgamentos que se revelaram inexatos. Quantas vêzes baseou uma escolha em sua intuiçăo, e quantas vêzes os pretendentes assim escolhidos preencheram suas expectativas? E quem poderá dizer quantos pretendentes ca- 
pazes êle rejeitou porque deixaram de acender a centelha necessária? Empatia às vêzes pode ser fundamental na seleção, mas preferir fiar-se nela, em lugar de num sistema de PED, requer cuidadosa e honesta diagnose dos desempenhos passados da pessoa.

\section{MOTIVOS ULTERIORES}

Cuidadosa e honesta autodiagnose tem cabimento também quando se chega a outro problema referente ao toque humano: a possibilidade de que o defensor do valor da interpretação humana possa ter alguns motivos ulteriores. Que aconteceria se um programa impessoal igualasse seu desempenho, ou o melhorasse? Também, se êle vê a avaliação de outra pessoa como o último baluarte de sua expressão pessoal, resistirá fortemente a abrir mão dessa prerrogativa para o computador. Terá a mesma reação, caso sinta prazer nas suas obrigaçōes, não apenas porque simbolizam suas habilidades incomuns, mas porque elas the dão poder sôbre os outros.

$\mathrm{Em}$ adição às inadequações mencionadas antes, tal como o malôgro de identificar todos os candidatos potenclais, os procedimentos de seleção tradicionais são susceptíveis de distorção motivada pela busca de necessidades pessoais. Gerentes de seleção orgulham-se de sua sensibilidade aos matizes interpessoais, e são capazes de manter sua autoconfiança, em parte, pela ausência de verificações precisas da validade de seus julgamentos. Como primeiro passo, os procedimentos computadorizados poderiam servir como técnica de validação para estudar decisōes de seleçăo humana; nesse caso, a automatização total seria um grande pulo para frente, e lá ir-se-ia seu emprêgo, como êle o vê.

O homem se sente reassegurado por sua fé na própria raridade e centralidade no esquema do universo, assim o mêdo de perder a chefia pode ditar muitas políticas de decisōes. Se êste mêdo é realístico, nossa engenhosidade pode nos providenciar defesas eficientes. Se é injustificado, devemos não permitir que êle intervenha na evolução de meios mais eficazes de utilizar nossas próprias capacidades. De qualquer modo, devemos distinguir entre os problemas tecnológi$\cos$ e julgamentos de valor quando formos pesar a praticabilidade de sistemas computadorizados de seleção. 